\title{
Development of an evidence-based individualized transition plan for spina bifida
}

\author{
Betsy Hopson, MSHA, ${ }^{1,2}$ Elizabeth N. Alford, MD,1 Kathrin Zimmerman, BA, ${ }^{1}$ \\ Jeffrey P. Blount, MD, 1,2 and Brandon G. Rocque, MD, MS'1 \\ 1'Department of Neurosurgery and 2Division of Pediatric Neurosurgery, University of Alabama at Birmingham, Alabama
}

OBJECTIVE In spina bifida (SB), transition of care from the pediatric to adult healthcare settings remains an opportunity for improvement. Transition of care is necessarily multidimensional and focuses on increasing independence, autonomy, and personal responsibility for health-related tasks. While prior research has demonstrated that effective transition can improve health outcomes and quality of life while reducing healthcare utilization, little is known about the most advantageous transition program components/design. The individualized transition plan (ITP) was developed to optimize the readiness of the adolescent with SB for adult healthcare. The ITP is a set of clearly articulated, mutually developed goals that arise from best available data on successful transition and are individualized to meet the individual challenges, needs, and attributes of each patient and family.

METHODS Prospectively completed ITPs were retrospectively reviewed from June 2018 to May 2019. Demographic and disease characteristics were collected, and specific goals were reviewed and categorized.

RESULTS Thirty-two patients with an ITP were included. The cohort was 50\% male and had a mean age of 16.4 years. For goal 1 (maximize education), the most common goal was to complete a career interest survey (44\%), followed by researching application/admission requirements for programs of interest (25\%), shadowing in and/or visiting a workplace (16\%), and improving high school performance (16\%). For goal 2 (bowel management), most patients (59\%) had a working bowel program with few or no bowel accidents. Eight patients $(25 \%)$ were having more than the desired number of bowel accidents and received formal consultation with a gastroenterologist. Five patients (16\%) needed only minor adjustments to their bowel management regimen. Goal 3 (SB program coordinator goal) focused on documenting medical and/or surgical history for the majority of patients $(66 \%)$. Other goals aimed to increase patient communication in healthcare settings or utilize available community resources.

CONCLUSIONS The authors developed an evidence-based ITP that focuses around 5 goals: maximizing education, bowel continence, and goals set by the SB clinic coordinator, parent/caregiver, and patient. Although developed for the authors' SB clinic, the ITP concept is applicable to transition of care in any chronic childhood illness.

https://thejns.org/doi/abs/10.3171/2019.7.FOCUS19425

KEYWORDS spina bifida; transition care; evidence-based medicine; adult care; continuity of care

$\mathrm{M}$ YELOMENINGOCELE is the most common form of spina bifida (SB) and results in varying degrees of paraparesis or paraplegia, hydrocephalus, neurogenic bowel and bladder, scoliosis, cognitive delay, and a variety of orthopedic and urological complications. . $^{1,3,6}$, ${ }_{10,15}$ Because of the inherently interdisciplinary nature of this condition, interdisciplinary "team style" clinic visits are common. Children's of Alabama (COA) developed an interdisciplinary pediatric SB clinic in 1993 and included providers from pediatric neurosurgery, pediatric orthopedics, pediatric rehabilitation medicine, and pediatric urology. Over time, this has grown to also include specialists from sleep medicine, gastroenterology, and other allied health specialties (e.g., wound care, orthotics, nutrition, and physical therapy).

By 2010, we had more patients reaching adulthood than we had new babies being born with myelomeningocele. As a result, the COA program began to develop partnerships

ABBREVIATIONS COA = Children's of Alabama; IEP = individualized education program; ITP = individualized transition plan; $\mathrm{LCM}=$ lifetime care model; $\mathrm{QOL}=$ quality of life; $\mathrm{SB}=$ spina bifida; TRAQ = Transition Readiness Assessment Questionnaire; UAB = University of Alabama at Birmingham.

SUBMITTED May 29, 2019. ACCEPTED July 29, 2019.

INCLUDE WHEN CITING DOI: 10.3171/2019.7.FOCUS19425. 
TABLE 1. Transition binder contents

\begin{tabular}{|c|c|}
\hline Section Title & Content \\
\hline Tools for transition & $\begin{array}{l}\text { Individual transition flow sheet } \\
\text { Transition youth to an adult healthcare } \\
\text { provider }\end{array}$ \\
\hline Basic information & $\begin{array}{l}\text { Patient profile } \\
\text { Insurance information } \\
\text { Consultants } \\
\text { Current status of sensory \& ability } \\
\quad \text { information } \\
\text { Pharmacy information }\end{array}$ \\
\hline Medical information & $\begin{array}{l}\text { Medication sheet } \\
\text { Problem list } \\
\text { Diagnostic tests } \\
\text { CT/MRI scans } \\
\text { Laboratory tests }\end{array}$ \\
\hline Bowel management & $\begin{array}{l}\text { Bowel management \& transition } \\
\text { Interventions based on assessment of } \\
\text { bowel patterns } \\
\text { Medications used for continence } \\
\text { management } \\
\text { Bowel diary } \\
\text { Key facts about managing bowel } \\
\text { incontinence } \\
\text { Anatomy of the bowel }\end{array}$ \\
\hline \multicolumn{2}{|l|}{ Urology } \\
\hline \multicolumn{2}{|l|}{ Skin care } \\
\hline \multicolumn{2}{|l|}{ Education/career planning } \\
\hline Support services & $\begin{array}{l}\text { Support services } \\
\text { Healthcare power of attorney }\end{array}$ \\
\hline \multicolumn{2}{|l|}{ Housing \& transportation } \\
\hline Legal considerations & \\
\hline
\end{tabular}

with adult colleagues at the University of Alabama at Birmingham (UAB) to develop and refine an infrastructure to support transition and adult SB clinic development. Research in the domain of transition of care has shown that transition must be comprehensive, addressing medical, vocational, educational, and psychosocial needs. ${ }^{12-14} \mathrm{~A}$ main focus for transition of care is increasing personal responsibility for health-related tasks, although the process also involves gaining autonomy and independence from caregivers and planning for their future. ${ }^{11,13}$ Poorly executed transition can result in fragmented care, increased hospitalizations, and worse outcomes. ${ }^{14,16}$ In 2016, a Cochrane Database review of studies focused on transition to adult care for adolescents with chronic health conditions found a paucity of high-quality research, with limited ability to evaluate the efficacy of transition interventions across the spectrum of chronic health conditions. ${ }^{2}$ The Agency for Health Care Research and Quality has also identified the crucial need for more information on and careful assessment of management paradigms that govern care for patients with chronic health conditions. ${ }^{9}$ There is a need for research on specific transition strategies and paradigms, long-term outcomes studies, cost-effectiveness measures, and methods for evaluating success of transition. To this end, our SB program has engaged in a concerted effort to study and improve the process of transition to adult care for adolescents with SB and their families.

Initially we observed a large cohort of young adult patients whose needs were being inconsistently and marginally met. Over time, we revised our practice plan and developed the lifetime care model (LCM)., ${ }^{3,6,10}$ The LCM was adopted for the purpose of ensuring that 1) age-appropriate strategies and locations were utilized, and 2) individualized care was organized under a longitudinal paradigm incorporating key components of transition for each state of care throughout life. The LCM centers on dedicated, interdisciplinary clinics under the COA/UAB SB program umbrella for each phase of a patient's life (prenatal, childhood, transition/adult). The LCM also includes established best practices and standardized management protocols derived from best available medical evidence.

With the development of the LCM, transition teaching initially began at 19 years of age and consisted of merely an exchange of information on the new clinic location, names and contact information for the adult care team, and general expectations. After a few years of experience, we realized that although we had solved the initial transition problem by developing an adult clinic where patients could be seen, our patients and their families were not prepared for either transition or the adult healthcare model. This led to a new transition initiative, including earlier entry into transition services and intentional guidance throughout the transition process.

The ultimate result of our transition initiative was the development of an individualized transition plan (ITP). The ITP is loosely structured like an individualized education program (IEP), which serves to define and direct the specific educational protocol for an individual with learning disabilities or challenges. Analogously, an ITP serves to individualize and optimize transition care within best-practice paradigms.

The purpose of the ITP is to optimize the readiness of the adolescent with SB for adult healthcare. Fundamentally, the ITP is a set of clearly articulated, mutually developed and agreed upon goals that are individualized for each patient and family. They arise from best available data on successful transition and are designed to meet the individual challenges, needs, and attributes of each patient and family. Logistically, patients receive their transition binder (Table 1), including their first ITP, and their first transition counseling session at 14 years of age. The ITP then becomes the framework for annual transition education and guides the clinical care team to deliver the educational information needed for each step of successful transition.

At each annual clinic visit, beginning at 13 years of age, patients complete the Transition Readiness Assessment Questionnaire (TRAQ), a "validated, patient-centered questionnaire that providers and families can use to assess youths' ability to make appointments, understand their medications and develop other skills needed for transition to adult care." ${ }^{, 2,9}$ The TRAQ is appropriate for transition to adult care for any chronic health condition. To complement the general skills assessed in the TRAQ, we worked with the authors to develop a 12-item supplemen- 
tal questionnaire to assess self-management skills specific for SB (TRAQ-SB), including urine and stool continence management, skin monitoring, and hydrocephalus/shunt maintenance.

Screening for quality of life (QOL) and depression is also performed via the Quality of Life Assessment in Spina Bifida and the Patient Health Questionnaire-9.

Annually, until 20 years of age, the ITP is modified to continue to build on prior goals. For our SB clinic, the ITP consists of 5 prioritized goals. These goals are set with the patient by the SB program coordinator (B.H.) and the goals are described to the patient as a "contract" between the patient and the SB program. Although the SB program coordinator is responsible for developing the ITP with patients at our institution, this could be performed by a nurse, social worker, or counselor. Goals are modified with the patient until a measurable action item is reached that the patient agrees to complete prior to the next SB clinic visit. The goals are written on the patient's ITP and also included in the patient's medical record. Below, we describe the rationale for how each of the goals are set.

\section{Five Goals of the ITP \\ Goal 1: Maximize Education}

QOL is known to decrease as individuals with a disability age. ${ }^{4,11}$ Anecdotally, we observed a similar pattern among patients in our interdisciplinary adult SB clinic. Furthermore, young adults with SB are at increased risk of isolation within their communities and are less likely to leave home, attend college, obtain employment, have a romantic relationship, and maintain friendships than their peers. ${ }^{1,711}$ In an effort to quantify this observation, we analyzed data from the adult SB clinic, comparing patients who self-identified as "permanently disabled" to those who worked, were in school, volunteered, or reported doing anything regularly outside the home., ${ }^{3,6}$ The only variables independently associated with self-identification as "permanently disabled" were lower level of education and bowel incontinence. Furthermore, both of these showed a dose/response relationship, with higher levels of education and less frequent bowel incontinence associated with less "permanent disability."

In response to this study, the first goal in the ITP is to maximize education. This encourages consideration of life aspirations and goals that need to be met incrementally to progress toward career and life goals. Vocation and career choices are central, but not exclusive. Education must be considered in its broader context as promoting critical thinking, independence, effective communication, self-awareness, and a broader context of life experience. A job, vocation, and career are important objectives for which action items are developed. Examples of action items might include completing a career interest survey, visiting local colleges or technical schools to learn about degree programs and disability services, finding volunteer opportunities in the industry of interest, and reaching out to businesses to visit their workplace or offer volunteer services. Goal 1 may also include discussion of necessary disability accommodations and/or adjustment of plans based on physical capabilities.

\section{Goal 2: Working Bowel Program}

Given the importance of bowel continence as a factor in self-perception of disability and overall QOL, 3,6,10 the second goal of the ITP involves the bowel program. Our goal as a program is to ensure that all adolescents and young adults leave the pediatric environment with a working bowel program. Central to this program is the attainment of patient and family goals for evacuation and continence with no unplanned bowel events. Sometimes, this can be accomplished with diligent attention to simple bowel management strategies including bowel schedules, laxatives, enemas, and dietary fiber or bulk agents. When appropriate, specialists from gastroenterology, surgery, or urology are included, and surgical options such as appendicocecostomy are discussed.

\section{Goals 3-5: Patient, Family, and Provider Goals}

The third, fourth, and fifth goals are set based on the results of the TRAQ-SB, medical and personal history, health status, and data from other screening tools. Goal 3 is set by the clinic's SB coordinator and strives to focus on increasing independence and autonomy in interfacing with the medical care team. Goal 3 examples include tracking medical and surgical history in the transition binder, encouraging patient communication with the physician (instead of parents), and making medical appointments.

Goal 4 is set by the patient's parent/caregiver and does not necessarily have to relate directly to the child's healthcare. Parents/caregivers are told to select one thing their child could do or a skill they could master to improve independence. Examples include making the bed 3 days per week without being told, catheterize on schedule without instruction, or limit television to 1 hour daily.

The fifth, and final, goal is set by the patient himself/ herself. Patients are encouraged to look inward and reflect on an area in which they would like to begin to improve. Examples may include things like the patient making a commitment to improve self-care through daily hygiene, learning to cook, or improving nutrition strategies. An example of a completed ITP is shown in Fig. 1.

\section{Methods}

Prospectively collected ITP data were retrospectively reviewed for the time period from June 2018 to May 2019. Patients were identified from archived SB clinic schedules and their ITP was obtained. All ITPs were developed with patients and their families by the SB program coordinator (B.H.). Additional demographic, diagnosis, and lesionlevel data were obtained from the National Spina Bifida Patient Registry. ITP goals were reviewed and grouped into categories based on similarity. Descriptive statistics were applied to quantitative variables.

\section{Results}

Since June 2018, 32 patients have received an ITP. The cohort is composed of 16 males and 16 females with a mean age of 16.4 years (range 14.0-19.1 years). Most patients $(\mathrm{n}=23 ; 71.9 \%)$ are Caucasian/not Hispanic or Latino, while 5 (15.6\%) are African American, 3 (9.4\%) 


\section{Individual Transition Plan (ITP)}

Instructions: This plan will be developed with your Spina Bifida team and it will become part of your medical record.

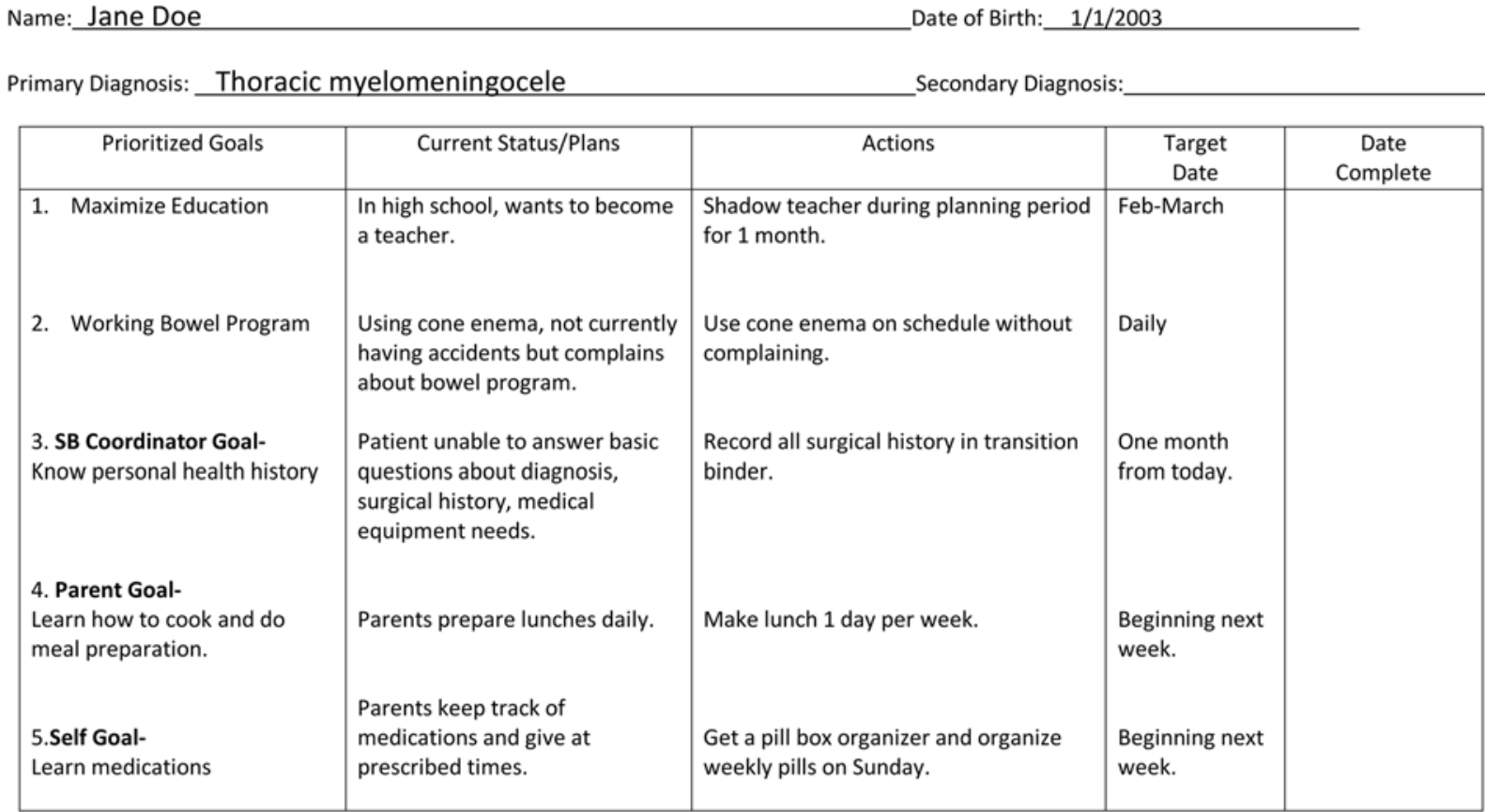

Initial Date of Plan: Last Updated:

Parent/Caregiver Signature: Clinician Signature

Transitioning Patient Signature: Care Staff Phone: $205-638-5281$

FIG. 1. Example of an ITP.

are Hispanic or Latino, and 1 (3.1\%) is American Indian. Thirty-one patients $(96.9 \%)$ have a diagnosis of myelomeningocele, 30 of whom have hydrocephalus; 1 patient has a lipomyelomeningocele. Functional lesion level is midlumbar for 11 patients $(34.4 \%)$, sacral for $9(28.1 \%)$, high-lumbar for 5 (15.6\%), low-lumbar for 4 (12.5\%), and thoracic for $3(9.4 \%)$.

For goal 1 (maximizing education) 11 patients (34.4\%) were interested in attending college and/or pursuing careers requiring a college degree. Fields of proposed study included engineering, nursing, teaching, speech pathology, mental health counseling, and paralegal services. Seven patients $(21.9 \%)$ planned to attend technical or vocational school, 2 patients $(6.3 \%)$ wished to directly enter the workforce, 1 patient (3.1\%) planned to join the armed forces, and 11 patients $(34.4 \%)$ had no specific plans. The most common goal was to complete a career interest survey (n $=14 ; 43.8 \%$ ), which is included in the patient's transition binder. Other common goals were researching application/admission requirements for programs of interest $(\mathrm{n}=$ $8 ; 25 \%)$, shadowing in and/or visiting a workplace $(\mathrm{n}=5$; $15.6 \%)$, and improving high school performance $(\mathrm{n}=5$; 15.6\%; Fig. 2).
For goal 2 (bowel program), most patients ( $\mathrm{n}=19$; $59.4 \%$ ) had a working bowel program with few or no bowel accidents. For these patients, their goals focused on improving independence in bowel management and notifying the SB care team if they developed new bowel-related issues or concerns. Eight patients (25\%) were having more than the desired number of bowel accidents and received formal consultation with a gastroenterologist. Five patients $(15.6 \%)$ needed only minor adjustments to their bowel management regimen.

Goal 3, set by the SB program coordinator, most commonly involved documenting some aspect of the patient's health history including medical problems, surgical history, and/or medical supplies used $(n=21 ; 65.6 \%)$. Other goals encouraged communication with physicians by the patient (instead of the caregiver; $n=7 ; 21.9 \%$ ), joining Lakeshore Foundation (a local organization for individuals with chronic physical disability), researching options for education/employment after high school, or obtaining an IEP.

Goals 4 and 5 are individualized to the patient and selected by the patient and his/her caregivers. These are often set after the SB clinic appointment, so all data were not 


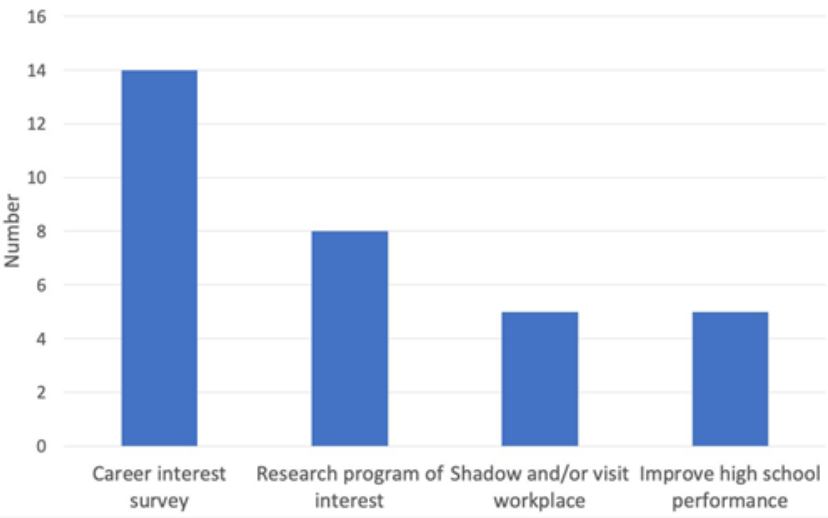

FIG. 2. Bar chart demonstrating specific task items to achieve goal 1 (maximize education).

available for review. Some examples include clean room twice weekly, shower independently, get in no fights at school, and make bed daily during school week.

\section{Discussion}

Our transition program and ITP have been well received by patients and their families. Based on our experience thus far, there is a lot of commonality in ITP goals between patients. For example, all patients could be grouped into 1 of 5 categories for goal 1 . This could simply reflect a nascent program and small sample size, where increasing diversity in goals would be expected with greater ITP use. Alternatively, it may suggest that transition age patients with SB have similar areas for improvement or unmet needs. Our data at this stage are preliminary; it remains to be seen whether patients engage with the ITP goals and whether the ITP has a meaningful impact on improving preparedness for transition. Given our small sample size, we were unable to evaluate whether factors such as lesion level, race, or age significantly influenced ITP effectiveness.

While the focus of our current research is to promote readiness of the patient for the adult healthcare model, there is also considerable work to be done to ensure that the adult healthcare system is designed and ready to provide optimal care for patients with complex medical conditions. An obvious opportunity for improvement is the incorporation of technology into the transition process, be it through use of a mobile health tracking application or making the ITP available digitally. The transition binder is currently distributed in paper form. A digital "binder" may be more user-friendly for digitally savvy adolescents, less prone to misplacement/loss, and/or enable use of learning strategies like gamification..$^{5,7}$

A formalized transition program and the ITP open up myriad new avenues for research in transition. The first category of research is defining what is "typical" for transition. The second category involves identifying risk factors for suboptimal transition and/or behaviors predictive of a successful transition. The third category of study is development of interventions designed to improve a specific aspect of transition. And finally, the fourth category of research is validating and confirming findings of other groups. We are currently exploring research questions across the first 3 categories, such as: What are typical TRAQ and TRAQ-SB scores, and how do those change over time? How prevalent is depression in this cohort and how does comorbid depression impact the transition process? Do patients who have a formalized ITP have better health and/or psychosocial outcomes than those who do not? We are also conducting a randomized clinical trial using telemedicine to conduct more frequent follow-up and transition counseling visits. ${ }^{7,8}$ Longitudinal data from these and other studies will inform our practice and generate hypotheses for future research.

The cooperative nature of this type of research cannot be overstated. While SB is the most common birth defect involving the CNS, its management is largely clustered around large academic pediatric hospitals. Multiinstitutional research studies and large national registries leverage larger sample sizes and a more diverse patient population. Studies that would otherwise be impractical due to slow patient accrual or small sample size become feasible. Cooperative studies also enable cross-pollination of ideas, and development and application of evidence-based best practices.

\section{Conclusions}

We have developed an evidence-based ITP that focuses around 5 goals: maximizing education, bowel continence, and goals set by the SB clinic coordinator, parent/caregiver, and patient, respectively. Although developed for our SB clinic, the ITP concept is applicable to transition of care in any chronic childhood illness. Preliminary experience suggests that it adds structure and value to the process of transition. Its simplicity is inviting and promotes compliance while its comprehensiveness and alignment with principles of best practice in transition ensure substance and value to patients and families. Patients become more actively involved in their care, and parents are relieved that a long-term vision for care is dynamically initiated and that young adults are prompted to think autonomously in terms of self-care, education, vocation, and greater self-awareness and independence. Future studies should be collaborative and aim to define standards, identify risk factors, develop novel interventions, and validate existing research.

\section{Acknowledgments}

Dr. Alford completed this work as the UAB Department of Neurosurgery Women's Leadership Council Research Scholar.

\section{References}

1. Bellin MH, Dicianno BE, Levey E, Dosa N, Roux G, Marben $\mathrm{K}$, et al: Interrelationships of sex, level of lesion, and transition outcomes among young adults with myelomeningocele. Dev Med Child Neurol 53:647-652, 2011

2. Campbell F, Biggs K, Aldiss SK, O’Neill PM, Clowes M, McDonagh J, et al: Transition of care for adolescents from paediatric services to adult health services. Cochrane Database Syst Rev 4:CD009794, 2016

3. Davis MC, Hopson BD, Blount JP, Carroll R, Wilson TS, 
Powell DK, et al: Predictors of permanent disability among adults with spinal dysraphism. J Neurosurg Spine 27:169177, 2017

4. East Tennessee State University: Transition Readiness Assessment Questionnaire. ETSU.edu (https://www.etsu.edu/ com/pediatrics/traq/) [Accessed August 12, 2019]

5. GotTransition.org: GotTransition.org - Health Care Providers. GotTransition.org (https://www.gottransition.org/ providers/index.cfm) [Accessed August 12, 2019]

6. Hopson B, Rocque BG, Joseph DB, Powell D, McLain ABJ, Davis RD, et al: The development of a lifetime care model in comprehensive spina bifida care. J Pediatr Rehabil Med 11:323-334, 2018

7. Kapp KM: The Gamification of Learning and Instruction: Game-Based Methods and Strategies for Training and Education. San Francisco: Pfeiffer, 2012

8. Kuhn E: Telemedicine in Spina Bifida Transition: A Pilot Study. NCT03466996. ClinicalTrials.gov (https:// clinicaltrials.gov/ct2/show/NCT03466996) [Accessed August 12, 2019]

9. McPheeters M, Davis AM, Taylor JL, Brown RF, Potter SA, Epstein RA Jr: Transition Care for Children With Special Health Needs. Rockville, MD: Agency for Healthcare Research and Quality, 2014 (http://www.ncbi.nlm.nih.gov/ books/NBK222123/) [Accessed August 12, 2019]

10. Rocque BG, Bishop ER, Scogin MA, Hopson BD, Arynchyna AA, Boddiford CJ, et al: Assessing health-related quality of life in children with spina bifida. J Neurosurg Pediatr 15:144-149, 2015

11. Seeley A, Lindeke L: Developing a transition care coordination program for youth with spina bifida. J Pediatr Health Care 31:627-633, 2017

12. Stam H, Hartman EE, Deurloo JA, Groothoff J, Grootenhuis MA: Young adult patients with a history of pediatric disease: impact on course of life and transition into adulthood. J Adolesc Health 39:4-13, 2006

13. Verhoof E, Maurice-Stam H, Heymans H, Grootenhuis M: Growing into disability benefits? Psychosocial course of life of young adults with a chronic somatic disease or disability. Acta Paediatr 101:e19-e26, 2012

14. White PH, McManus MA, McAllister JW, Cooley WC: A primary care quality improvement approach to health care transition. Pediatr Ann 41:e1-e7, 2012

15. Winn HR: Youmans and Winn Neurological Surgery, ed 7. Philadelphia: Elsevier, 2016

16. Zukerman JM, Devine KA, Holmbeck GN: Adolescent predictors of emerging adulthood milestones in youth with spina bifida. J Pediatr Psychol 36:265-276, 2011

\section{Disclosures}

The authors report no conflict of interest concerning the materials or methods used in this study or the findings specified in this paper.

\section{Author Contributions}

Conception and design: Hopson, Blount, Rocque. Acquisition of data: Hopson, Alford, Zimmerman. Analysis and interpretation of data: Hopson, Alford. Drafting the article: Hopson, Alford, Zimmerman. Critically revising the article: all authors. Reviewed submitted version of manuscript: all authors. Approved the final version of the manuscript on behalf of all authors: Hopson. Administrative/technical/material support: Hopson. Study supervision: Hopson, Blount, Rocque.

\section{Supplemental Information \\ Videos \\ Video Abstract. https://vimeo.com/357575327.}

\section{Correspondence}

Betsy Hopson: University of Alabama at Birmingham, AL. betsy.hopson@childrensal.org. 